\title{
Mitochondrial DNA variation in sudden cardiac death: a population-based study
}

\author{
Laura Kytövuori $^{1,2,3}$ (D) Juhani Junttila ${ }^{2,4} \cdot$ Heikki Huikuri ${ }^{2,4} \cdot$ Sirkka Keinänen-Kiukaanniemi $^{2,5,6} \cdot$ Kari Majamaa $^{1,2,3}$. \\ Mika H. Martikainen ${ }^{7}$
}

Received: 12 February 2019 / Accepted: 22 May 2019 / Published online: 31 May 2019

(C) The Author(s) 2019

\begin{abstract}
Cardiomyopathy and cardiac conduction defects are common manifestations of mitochondrial disease. Previous studies suggest that clinically asymptomatic individuals harbouring pathogenic mitochondrial DNA (mtDNA) mutations in the cardiac muscle may have sudden cardiac death (SCD) as the first manifestation of mitochondrial disease. We investigated the contribution of pathogenic mtDNA point mutations and mtDNA haplogroups in cardiac muscle in a cohort of 280 Finnish subjects that had died from non-ischaemic SCD with the median age of death at 59 years and in 537 population controls. We did not find any common or novel pathogenic mutations, but the frequency of haplogroup H1 was higher in the SCD subjects than that in 537 population controls (odds ratio: 1.76, confidence interval 95\%: 1.02-3.04). We conclude that, at the population level, pathogenic point mutations in mtDNA do not contribute to non-ischaemic SCD, but natural variation may modify the risk.
\end{abstract}

Keywords Mitochondrial disease $\cdot$ Mitochondrial DNA $\cdot$ Mitochondrial haplogroups $\cdot$ Non-ischaemic $\cdot$ Sudden cardiac death

$\begin{array}{ll}\text { Abbreviations } \\ \text { CAD } & \begin{array}{l}\text { coronary artery disease } \\ \text { CM }\end{array} \\ \text { cardiomyopathy } \\ \text { MELAS } & \begin{array}{l}\text { Mitochondrial encephalomyopathy, lactic acido- } \\ \text { sis and stroke-like episodes }\end{array} \\ \text { mtDNA } & \begin{array}{l}\text { mitochondrial DNA } \\ \text { OXPHOS }\end{array} \\ \text { oxidative phosphorylation } \\ \text { SCD } & \text { sudden cardiac death }\end{array}$

Electronic supplementary material The online version of this article (https://doi.org/10.1007/s00414-019-02091-4) contains supplementary material, which is available to authorized users.

Laura Kytövuori

laura.kytovuori@oulu.fi

Juhani Junttila

juhani.junttila@oulu.fi

Heikki Huikuri

heikki.huikuri@oulu.fi

Sirkka Keinänen-Kiukaanniemi

sirkka.keinanen-kiukaanniemi@oulu.fi

Kari Majamaa

kari.majamaa@oulu.fi

Mika H. Martikainen

mikmar@utu.fi

\section{Introduction}

Sudden cardiac death (SCD) accounts for 15-20\% of all deaths, and the population rates range between 50 and 100/ 100,000 [1]. In the Finnish population, the annual incidence of SCD has been estimated to be 56.9/100,000 [2]. Coronary artery disease (CAD) is the most common ( $~ 80 \%)$ cause of $\mathrm{SCD}$; cardiomyopathy $(\mathrm{CM})$ and fibrotic $\mathrm{CM}$ explain about a

1 Research Unit of Clinical Neuroscience, University of Oulu, PO Box 5000, 90014 Oulu, Finland

2 Medical Research Center Oulu, Oulu University Hospital and University of Oulu, Oulu, Finland

3 Department of Neurology, Oulu University Hospital, PO Box 20, 90029 Oulu, Finland

4 Research Unit of Internal Medicine, University of Oulu, PO Box 5000, 90014 Oulu, Finland

5 Center for Life Course Health Research, University of Oulu, PO Box 5000, 90014 Oulu, Finland

6 Healthcare and Social Services of Selänne, Pyhäjärvi, Finland

7 Division of Clinical Neurosciences, University of Turku and Turku University Hospital, Kiinamyllynkatu 4-8, 20520 Turku, Finland 
third of non-ischaemic SCD events [2]. Among younger SCD subjects, however, monogenic disease leading to cardiomyopathy and various arrhythmias plays a major role [3]. Nonischaemic SCD, particularly among young individuals, is etiologically multifactorial, and in many instances, no single causal factor can be confirmed with certainty [4].

Mitochondrial diseases can manifest as cardiomyopathy, conduction defects and even SCD [5]. The m.3243A > G point mutation in the MT-TL1 gene is the most common pathogenic mtDNA mutation and causes variable clinical manifestations [6]. Carriers of the m.3243A > G mutation have an increased risk of death, and sudden death resulting from cardiac complications is not uncommon among them [7, 8]. Importantly, clinically asymptomatic carriers of m.3243A > $G$ may harbour the mutation with a high portion (heteroplasmy) in the cardiac tissue, predisposing them to failure of heart energy production and SCD [8]. Cardiac manifestations seem to be particularly prevalent in association with certain other mtDNA mutations, such as m.3260A > G $[9,10]$.

Sequence variation in mtDNA may be nonneutral, as mtDNA haplogroups have been associated with disease risks and functional differences have been observed in oxidative phosphorylation (OXPHOS) and production of reactive oxygen species [11-13]. Specific mtDNA haplogroups have been associated with many traits or diseases such as longevity [14], diabetes mellitus [15], obesity [16] and Parkinson's disease [17]. Despite the paramount role of mitochondrial energy production in cardiac health, there are no previous studies on the role of mtDNA mutations and haplogroups in SCD in population. Therefore, we decided to investigate the frequency of pathogenic mtDNA mutations and that of mtDNA haplogroups in a large, population-based autopsy cohort of Finnish subjects that died from non-ishaemic SCD.

\section{Subjects and methods}

\section{Study population}

Study subjects consisted of persons who had died outside hospital in 2006-2012. Here, SCD was defined as a witnessed cardiac death within $6 \mathrm{~h}$ of the onset of symptoms, or within $24 \mathrm{~h}$ since the last time the victim was seen alive in good health. Autopsies were carried out at the Department of Forensic Medicine of the University of Oulu. The cardiac cause of death was confirmed in the autopsy and noncardiac sudden deaths were excluded, as were individuals who had a previous diagnosis of CAD, or who were diagnosed with CAD based on autopsy findings. There were altogether 388 non-ischaemic SCDs [18]. The medical data were collected from the electronic medical records, postmortem examination reports and from questionnaires filled out by the closest relatives of the study subjects [18]. Patients diagnosed with alcoholic cardiomyopathy or infectious heart diseases were excluded from the analyses leaving 280 SCDs that were included in the study. The median age at death was 59 years (ranged from 1 to 90 years) (Table 1). Most of the subjects were diagnosed with cardiomegaly (ICD-10: I51.7) or hypertensive heart disease with or without heart failure (I11.0, I11.9, I13.2). The flowchart of study subject identification and genetic investigations is shown in the supplementary figure.

The controls were residents of the city of Oulu who were born in 1935 [19]. All the 1008 persons, who met the inclusion criteria on 1 October 1990, were invited to the study. Among the 768 participants, 537 persons gave their blood sample that was used to determine mtDNA haplogroup frequencies in the general population.

\section{Ethical statement}

High standard of ethics according to the WMA Declaration of Helsinki was applied in all investigations described in this manuscript. The research project was approved by the Ethics Committee of Oulu University Hospital (EETTMK 44/2002).

\section{Molecular genetic analyses}

The cardiac samples taken at autopsy were stored in paraffin. DNA from paraffin embedded tissue was extracted using QIAamp DNA FFPE Tissue Kit (Qiagen, Hilden, Germany). Because of the paraffin-embedded starting material, the extraction yielded fragmented mtDNA and, therefore, amplification was carried out using secondary polymerase chain reaction (PCR) of 41 overlapping fragments. We initially aimed at sequencing the entire mtDNA, but as the poor quality of FFPE-derived DNA became imminent, we were compelled to target our resources to obtaining the best possible data in the coding region. The fact that no disease-causing mutations have been found in the control region justified this approach. The reactions were done using Phire Hot Start II polymerase according to the provided protocols (Thermo Fisher Scientific, Waltham, MA, USA). Primers and detailed reaction conditions are available in supplementary Table 1. PCR products were sequenced using BigDyeTerminator v1.1 cycle sequencing kit (Applied Biosystems, Thermo Fisher Scientific) with 3500xL Genetic Analyzer (Applied Biosystems) in Biocenter Oulu Sequencing Core. DNA from the control blood samples was extracted by using QIAamp DNA Blood Midi Kit, and haplogroups were determined using restriction fragment length polymorphism (Thermo Fisher Scientific, New England Biolabs, Ipswich, MA, USA) as described previously [20].

We determined the common m.3243A $>\mathrm{G}$ and m.3260A > G mutations in 280 SCD subjects by sequencing and the entire coding region of mtDNA (m.577-m.16023) was sequenced in a sub-cohort of 91 young subjects (age at death 
Table 1 Causes of the sudden cardiac death (SCD) among 280 subjects deceased in 2006-2012 in Northern Osthrobothnia, Finland

\begin{tabular}{|c|c|c|c|c|c|c|c|}
\hline & ICD-10 & Young SCDs* & Men & Women & All SCDs & Men & Women \\
\hline$N$ & & 91 & 74 & 17 & 280 & 204 & 76 \\
\hline Age range (years) & & $20-55$ & $20-55$ & $26-55$ & $1-90$ & & \\
\hline \multicolumn{8}{|l|}{ Diagnosis $N(\%)$} \\
\hline Cardiomegaly & I51.7 & $40(44)$ & $35(47.3)$ & $5(29.4)$ & $110(39.3)$ & $85(41.7)$ & $25(32.9)$ \\
\hline Hypertensive heart disease & $\mathrm{I} 11.0, \mathrm{I} 11.9, \mathrm{I} 13.2$ & $29(31.9)$ & $23(31.1)$ & $6(35.3)$ & $124(44.3)$ & $87(42.6)$ & $37(48.7)$ \\
\hline Acute myocarditis & I40.9 & $6(6.6)$ & $3(4.1)$ & $3(17.6)$ & $11(3.9)$ & $7(3.4)$ & $4(5.3)$ \\
\hline Myocarditis in other diseases & I41.8 & - & - & - & $1(0.4)$ & - & $1(1.3)$ \\
\hline Dilated cardiomyopathy & $\mathrm{I} 42.0$ & $3(3.3)$ & $3(4.1)$ & - & $11(3.9)$ & $10(4.9)$ & $1(1.3)$ \\
\hline Hypertrophic cardiomyopathy & $\mathrm{I} 42.2$ & $3(3.3)$ & $3(4.1)$ & - & $6(2.1)$ & $5(2.5)$ & $1(1.3)$ \\
\hline Other/unspecified cardiomyopathy & I 42.8, I.42.9 & $3(3.3)$ & $2(2.7)$ & $1(5.9)$ & $7(2.5)$ & $5(2.5)$ & $2(2.6)$ \\
\hline Conductive heart block & $\mathrm{I} 45.8$ & $1(1.1)$ & $1(1.4)$ & - & $1(0.4)$ & $1(0.5)$ & - \\
\hline Ventricular arrhythmia & I47.0 & $1(1.1)$ & - & $1(5.9)$ & $1(0.4)$ & - & $1(1.3)$ \\
\hline Other/unspecified cardiac arrhythmia & I49.8, I49.9 & $2(2.2)$ & $2(2.7)$ & - & $2(0.7)$ & $2(1.0)$ & - \\
\hline Myocardial degeneration & $\mathrm{I} 51.5$ & $2(2.2)$ & $1(1.4)$ & $1(5.9)$ & $5(1.8)$ & $1(0.5)$ & $4(5.3)$ \\
\hline Unspecified heart disease & I51.9 & $1(1.1)$ & $1(1.4)$ & - & $1(0.4)$ & $1(0.5)$ & - \\
\hline
\end{tabular}

20-55 years). Because of mtDNA fragmentation, sequencing covered $100 \%$ of the coding region of mtDNA in 64 of the 91 samples and a mean of $77 \%$ (range, 48-96\%) in the remaining 27 samples. Mitochondrial DNA haplogroups could be determined in 78 out of the 91 young victims by using HaploGrep2 [21] with Phylotree 17 [22]. Odds ratios (OR) and 95\% confidence intervals (CI) of $95 \%$ were calculated for all haplogroups $[23,24]$.

\section{Results}

The m.3243A $>\mathrm{G}$ and m.3260A $>\mathrm{G}$ mutations were not detected in the cardiac tissue of 280 subjects that died from SCD. No previously reported or novel pathogenic mutations were found in the mtDNA sequences of 91 young SCD subjects (supplementary Table 2). One variant in rRNA (m.1923C > $\mathrm{T}$ ), two in tRNA genes (m.5646C $>\mathrm{T}, \mathrm{m} .5840 \mathrm{C}>\mathrm{T}$ ) and nine nonsynonymous variants in protein coding genes (m.4812G $>$ A, m.5164G $>$ A, m.5319A $>$ T, m.7114C $>$ T, m.7706G $>$ A, m.8156G $>$ A, m. $8776 \mathrm{C}>\mathrm{T}, \mathrm{m} .9333 \mathrm{C}>\mathrm{T}$, $\mathrm{m} .13718 \mathrm{G}>\mathrm{C}$ ) were considered rare as they were present in less than 10 sequences in the MITOMAP database (MITOMAP: A Human Mitochondrial Genome Database. http://www.mitomap.org, 2019). None of the rare variants in the protein coding genes were predicted to be pathogenic as assessed by PredictSNP [25]. The two variants in tRNA genes were benign according to the MitoTIP predictor for tRNA variants [26], and the rRNA variant has previously been found in controls [27].

The frequency of superhaplogroup HV was $56.4 \%$ among the SCD subjects while it was $44.7 \%$ in the population controls. The two most prevalent haplogroups among SCD subjects were $\mathrm{H} 1$ with a frequency of $27 \%$ and U5 with a frequency of $24 \%$ (Table 2). Other subhaplogroups of $\mathrm{H}$ accounted for $19 \%$ and other subhaplogroups of $\mathrm{U}$ accounted for $5.1 \%$ of the subjects. SCD was associated with haplogroup H1 with an OR of 1.76 (CI 95\%: 1.02-3.04, $p=0.043$ ). ORs for all other haplogroups were not significant.

\section{Discussion}

We did not find $\mathrm{m} .3243 \mathrm{~A}>\mathrm{G}$ or other pathogenic mtDNA mutations among the $280 \mathrm{SCD}$ subjects. Mutations were analysed in DNA from cardiac muscle, the clinically relevant tissue, that had been collected prospectively during a 7-year period in a defined population. In Finland, autopsy is required by law, when the death is not known to be caused by a disease or if the deceased had not been treated by a physician during the latest illness, or if the death was otherwise unexpected (Act on the Inquest into the Cause of Death 459/1973, Finnish Law). All subjects dying suddenly and unexpectedly were therefore autopsied and subjects with coronary heart disease or non-cardiac disease as the cause of death were excluded.

Mitochondrial diseases are common inherited neurological disorders, in which cardiac manifestations are among the core features $[5,28]$. The incidence of major adverse cardiac events has been reported to be increased especially among patients harbouring the m.3243A $>\mathrm{G}$ mutation or a single mtDNA deletion [29]. Analysis of heart rate variability has revealed altered cardiac autonomic regulation in patients with m.3243A $>$ G further indicating that regular follow-up of cardiac function is essential in these patients [29,30]. Moreover, 
Table 2 Frequencies of the mtDNA haplogroups and haplogroup clusters in victims of non-ischaemic sudden cardiac death $(N=78)$ and in population controls $(N=537)$

\begin{tabular}{llllllll}
\hline Haplogroup & SCD & SCD \% & Cluster \% & Controls & Controls \% & Cluster \% & OR (CI 95\%) \\
\hline H & 15 & 19.2 & 56.4 & 119 & 22.2 & 44.7 & $0.84(0.45-1.52)$ \\
H1 & 21 & 26.9 & & 93 & 17.3 & & $1.76^{*}(1.02-3.04)$ \\
V & 8 & 10.3 & & 28 & 5.2 & & $2.08(0.91-4.74)$ \\
U5 & 19 & 24.4 & & 144 & 26.8 & & $0.88(0.51-1.53)$ \\
U & 4 & 5.1 & 32.1 & 16 & 3.0 & 33.3 & $1.76(0.57-5.41)$ \\
K & 2 & 2.6 & & 19 & 3.5 & & $0.72(0.16-3.14)$ \\
J & 3 & 3.8 & 5.1 & 26 & 4.8 & 10.8 & $0.79(0.23-2.66)$ \\
T & 1 & 1.3 & & 32 & 6.0 & & $0.21(0.03-1.52)$ \\
W & 5 & 6.4 & 6.4 & 29 & 5.4 & 9.0 & $1.20(0.45-3.20)$ \\
I & & & & 9 & 1.7 & & \\
X & & & & 10 & 1.9 & & \\
Other & & & 12 & 2.2 & 2.2 & \\
\hline
\end{tabular}

$* p<0.05$

$C I$ confidence interval, $O R$ odds ratio cardiac examination should be provided to asymptomatic mutation carriers, who might have a high heteroplasmy in the heart, and SCD might be the first disease manifestation [8, 30].

Mitochondrial cardiomyopathy may result from several other mtDNA mutations [10], such as the m.3260A $>\mathrm{G}$ transition in MT-TL1 [9] causing maternally inherited cardiomyopathy. Intriguingly, the overlapping region of MT-ATP6 and MT$A T P 8$ seems to be a hotspot for mutations causing cardiomyopathy indicating that human heart is vulnerable to the dysfunction of mitochondrial ATPase [31, 32]. Cardiomyopathy has also been reported in rare cases with hearing impairment caused by m.1555A > G or Leber's hereditary optic neuropathy caused by $\mathrm{m} .11778 \mathrm{G}>\mathrm{A}[33,34]$. In addition, disrupted mtDNA maintenance can lead to decreased mtDNA copy number causing continuous energy deprivation and cardiomyopathy [35]. The mtDNA copy number has been shown to inversely correlate with the risk of SCD [36].

We found that superhaplogroup HV was more frequent among SCD subjects than among controls, and the difference could be attributed to 1.6-fold excess of haplogroup H1. Haplogroup $\mathrm{H}$ has previously been reported to be associated with dilated cardiomyopathy [37] and with a heart failure requiring heart transplant [38]. Interestingly, functional differences have been reported between haplogroups. For example, the oxygen consumption rate has been found to be decreased in haplogroup $\mathrm{H}$ when compared with haplogroup Uk [11]. Our results suggest that in population, haplogroup H1 may be a risk factor for non-ischaemic SCD.

Differences in ethnicity between the subjects and controls should be taken into consideration, even if both groups were ascertained from the population of Northern Ostrobothnia. The Finnish population has remained rather isolated up to the recent years and, consequently, non-European haplogroups were not found in the SCD subjects or the controls. However, there is a Saami population of 10,000 people in Finland and the frequency of mtDNA haplogroup $\mathrm{H}$ is exceptionally low among them [39]. In the province of Northern Ostrobothnia, there are 169 residents, whose native language is Saami (Statistics Finland; https://www.stat.fi/ index_en.html) and some 850 residents who are ethnically Saami given the proportion that one out of five Saami subjects has reported Saami language as the native language. These figures suggest that the Saami make $0.21 \%$ of the population of Northern Ostrobothnia. Hence, the probability of one and only one Saami subject among the 537 controls is 0.37 suggesting that it is unlikely that possible Saami individuals among the controls would deflate the results.

Our results suggest that in the general population, mtDNA mutations are a rare cause of non-ischaemic SCD. Cardiac investigations and follow-up should be targeted to individuals harbouring pathogenic mtDNA mutations associated with cardiac complications. Identification of such individuals requires increased awareness of mitochondrial disease in the general population and among health care professionals, with genetic counselling and offering genetic testing for at-risk family members. In addition, we report an association between SCD risk and mtDNA haplogroup $\mathrm{H} 1$, suggesting that variation of mitochondrial energetics modifies the risk of SCD in population.

Acknowledgements Päivi Kastell is acknowledged for her technical assistance.

Funding information Open access funding provided by University of Oulu including Oulu University Hospital. This work was supported by The Sigrid Jusélius Foundation, Finnish Foundation for Cardiovascular Research and by State Research Funding from Oulu University Hospital.

Data availability All data generated or analysed during this study are included in this published article and its supplementary information files. 
Compliance with ethical standards High standard of ethics according to the WMA Declaration of Helsinki was applied in all investigations described in this manuscript. The research project was approved by the Ethics Committee of Oulu University Hospital (EETTMK 44/ 2002).

Conflict of interest The authors declare that they have no conflict of interest.

Open Access This article is distributed under the terms of the Creative Commons Attribution 4.0 International License (http:// creativecommons.org/licenses/by/4.0/), which permits unrestricted use, distribution, and reproduction in any medium, provided you give appropriate credit to the original author(s) and the source, provide a link to the Creative Commons license, and indicate if changes were made.

\section{References}

1. Deo R, Albert CM (2012) Epidemiology and genetics of sudden cardiac death. Circulation 125:620-637

2. Hookana E, Junttila MJ, Puurunen VP, Tikkanen JT, Kaikkonen KS, Kortelainen ML, Myerburg RJ, Huikuri HV (2011) Causes of nonischemic sudden cardiac death in the current era. Heart Rhythm 8:1570-1575

3. Stallmeyer B, Schulze-Bahr E (2015) Cardiovascular disease and sudden cardiac death: between genetics and genomics. Eur Heart J 36:1643-1645

4. Anderson JH, Tester DJ, Will ML, Ackerman MJ (2016) Wholeexome molecular autopsy after exertion-related sudden unexplained death in the young. Circ Cardiovasc Genet 9:259-265

5. Bray AW, Ballinger SW (2017) Mitochondrial DNA mutations and cardiovascular disease. Curr Opin Cardiol 32:267-274

6. Nesbitt V, Pitceathly RD, Turnbull DM, Taylor RW, Sweeney MG, Mudanohwo EE et al (2013) The UK MRC mitochondrial disease patient cohort study: clinical phenotypes associated with the $\mathrm{m}$. 3243A> G mutation - implications for diagnosis and management. J Neurol Neurosurg Psychiatry 84:936-938

7. Majamaa-Voltti K, Turkka J, Kortelainen ML, Huikuri H, Majamaa $\mathrm{K}$ (2008) Causes of death in pedigrees with the $3243 \mathrm{~A}>\mathrm{G}$ mutation in mitochondrial DNA. J Neurol Neurosurg Psychiatry 79:209-211

8. Ng YS, Grady JP, Lax NZ, Bourke JP, Alston CL, Hardy SA, Falkous G, Schaefer AG, Radunovic A, Mohiddin SA, Ralph M, Alhakim A, Taylor RW, McFarland R, Turnbull DM, Gorman GS (2016) Sudden adult death syndrome in m. 3243A> G-related mitochondrial disease: an unrecognized clinical entity in young, asymptomatic adults. Eur Heart J 37:2552-2559

9. Zeviani M, Gellera C, Antozzi C, Rimoldi M, Morandi L, Villani F et al (1991) Maternally inherited myopathy and cardiomyopathy: association with mutation in mitochondrial DNA tRNALeu (UUR). Lancet 338:143-147

10. Bates MG, Bourke JP, Giordano C, d'Amati G, Turnbull DM, Taylor RW (2012) Cardiac involvement in mitochondrial DNA disease: clinical spectrum, diagnosis, and management. Eur Heart J 33:3023-3033

11. Gómez-Durán A, Pacheu-Grau D, López-Gallardo E, Díez-Sánchez C, Montoya J, López-Pérez MJ, Ruiz-Pesini E (2010) Unmasking the causes of multifactorial disorders: OXPHOS differences between mitochondrial haplogroups. Hum Mol Genet 19:3343-3353

12. Kenney MC, Chwa M, Atilano SR, Pavlis JM, Falatoonzadeh P, Ramirez C, Malik D, Hsu T, Woo G, Soe K, Nesburn AB, Boyer DS, Kuppermann BD, Jazwinski SM, Miceli MV, Wallace DC, Udar N (2013) Mitochondrial DNA variants mediate energy production and expression levels for $\mathrm{CFH}, \mathrm{C} 3$ and EFEMP1 genes: implications for age-related macular degeneration. PLoS One 8: e54339

13. Latorre-Pellicer A, Moreno-Loshuertos R, Lechuga-Vieco AV, Sánchez-Cabo F, Torroja C, Acín-Pérez R, Calvo E, Aix E, González-Guerra A, Logan A, Bernad-Miana ML, Romanos E, Cruz R, Cogliati S, Sobrino B, Carracedo Á, Pérez-Martos A, Fernández-Silva P, Ruíz-Cabello J, Murphy MP, Flores I, Vázquez J, Enríquez JA (2016) Mitochondrial and nuclear DNA matching shapes metabolism and healthy ageing. Nature 535:561565

14. Niemi AK, Hervonen A, Hurme M, Karhunen PJ, Jylhä M, Majamaa K (2003) Mitochondrial DNA polymorphisms associated with longevity in a Finnish population. Hum Genet 112:29-33

15. Martikainen MH, Rönnemaa T, Majamaa K (2013) Prevalence of mitochondrial diabetes in southwestern Finland: a molecular epidemiological study. Acta Diabetol 50:737-741

16. Ebner S, Mangge H, Langhof H, Halle M, Siegrist M, Aigner E, Paulmichl K, Paulweber B, Datz C, Sperl W, Kofler B, Weghuber D (2015) Mitochondrial Haplogroup T is associated with obesity in Austrian juveniles and adults. PLoS One 10:e0135622

17. Hudson G, Nalls M, Evans JR, Breen DP, Winder-Rhodes S, Morrison KE, Morris HR, Williams-Gray CH, Barker RA, Singleton AB, Hardy J, Wood NE, Burn DJ, Chinnery PF (2013) Two-stage association study and meta-analysis of mitochondrial DNA variants in Parkinson disease. Neurology 80:2042-2048

18. Junttila MJ, Hookana E, Kaikkonen KS, Kortelainen ML, Myerburg RJ, Huikuri HV (2016) Temporal trends in the clinical and pathological characteristics of victims of sudden cardiac death in the absence of previously identified heart disease. Circ Arrhythm Electrophysiol 9:e003723

19. Rajala U, Keinänen-Kiukaanniemi S, Uusimäki A, Reijula K, Kivelä SL (1995) Prevalence of diabetes mellitus and impaired glucose tolerance in a middle-aged Finnish population. Scand J Prim Health Care 13:222-228

20. Finnilä S, Lehtonen MS, Majamaa K (2001) Phylogenetic network for European mtDNA. Am J Hum Genet 68:1475-1484

21. Weissensteiner H, Pacher D, Kloss-Brandstätter A, Forer L, Specht G, Bandelt HJ, Kronenberg F, Salas A, Schönherr S (2016) HaploGrep 2: mitochondrial haplogroup classification in the era of high-throughput sequencing. Nucleic Acids Res 44:W58-W63

22. van Oven M (2015) PhyloTree build 17: growing the human mitochondrial DNA tree. Forensic Sci Int Genet 5:e392-e394

23. Szumilas M (2010) Explaining odds ratios. J Can Acad Child Adolesc Psychiatry 19:227-229

24. Sheskin DJ (2000) Handbook of parametric and nonparametric statistical procedures. Chapman \& Hall/CRC, Boca Raton

25. Bendl J, Stourac J, Salanda O, Pavelka A, Wieben ED, Zendulka J, Brezovsky J, Damborsky J (2014) PredictSNP: robust and accurate consensus classifier for prediction of disease-related mutations. PLoS Comput Biol 10:e1003440

26. Sonney S, Leipzig J, Lott MT, Zhang S, Procaccio V, Wallace DC, Sondheimer N (2017) Predicting the pathogenicity of novel variants in mitochondrial tRNA with MitoTIP. PLoS Comput Biol 13: e1005867

27. Raule N, Sevini F, Li S, Barbieri A, Tallaro F, Lomartire L, Vianello D, Montesanto A, Moilanen JS, Bezrukov V, Blanché H, Hervonen A, Christensen K, Deiana L, Gonos ES, Kirkwood TBL, Kristensen P, Leon A, Pelicci PG, Poulain M, Rea IM, Remacle J, Robine JM, Schreiber S, Sikora E, Eline Slagboom P, Spazzafumo L, Antonietta Stazi M, Toussaint O, Vaupel JW, Rose G, Majamaa K, Perola M, Johnson TE, Bolund L, Yang H, Passarino G, Franceschi C (2014) The co-occurrence of mt DNA mutations on different oxidative phosphorylation subunits, not detected by haplogroup analysis, affects human longevity and is population specific. Aging Cell 13: $401-407$ 
28. Gorman GS, Schaefer AM, Ng Y, Gomez N, Blakely EL, Alston CL, Feeney C, Horvath R, Yu-Wai-Man P, Chinnery PF, Taylor RW, Turnbull DM, McFarland R (2015) Prevalence of nuclear and mitochondrial DNA mutations related to adult mitochondrial disease. Ann Neurol 77:753-759

29. Wahbi K, Bougouin W, Béhin A, Stojkovic T, Bécane HM, Jardel C, Berber N, Mochel F, Lombès A, Eymard B, Duboc D, Laforêt P (2015) Long-term cardiac prognosis and risk stratification in 260 adults presenting with mitochondrial diseases. Eur Heart J 36: 2886-2893

30. Majamaa-Voltti K, Majamaa K, Peuhkurinen K, Mäkikallio TH, Huikuri HV (2004) Cardiovascular autonomic regulation in patients with 3243A> G mitochondrial DNA mutation. Ann Med 36:225231

31. Ware SM, El-Hassan N, Kahler SG, Zhang Q, Ma YW, Miller E et al (2009) Infantile cardiomyopathy caused by a mutation in the overlapping region of mitochondrial ATPase 6 and 8 genes. J Med Genet 46:308-314

32. Imai A, Fujita S, Kishita Y, Kohda M, Tokuzawa Y, Hirata T, Mizuno Y, Harashima H, Nakaya A, Sakata Y, Takeda A, Mori M, Murayama K, Ohtake A, Okazaki Y (2016) Rapidly progressive infantile cardiomyopathy with mitochondrial respiratory chain complex V deficiency due to loss of ATPase 6 and 8 protein. Int $\mathrm{J}$ Cardiol 207:203-205

33. Santorelli FM, Tanji K, Manta P, Casali C, Krishna S, Hays AP, Mancini DM, DiMauro S, Hirano M (1999) Maternally inherited cardiomyopathy: an atypical presentation of the mtDNA 12S rRNA gene A1555G mutation. Am J Hum Genet 64:295-300

34. Mimaki M, Ikota A, Sato A, Komaki H, Akanuma J, Nonaka I, Goto Y (2003) A double mutation (G11778A and G12192A) in mitochondrial DNA associated with Leber's hereditary optic neuropathy and cardiomyopathy. J Hum Genet 48:47-50

35. Viscomi C, Zeviani M (2017) MtDNA-maintenance defects: syndromes and genes. J Inherit Metab Dis 40:587-599
36. Zhang Y, Guallar E, Ashar FN, Longchamps RJ, Castellani CA, Lane J, Grove ML, Coresh J, Sotoodehnia N, Ilkhanoff L, Boerwinkle E, Pankratz N, Arking DE (2017) Association between mitochondrial DNA copy number and sudden cardiac death: findings from the atherosclerosis risk in communities study (ARIC). Eur Heart J 38:3443-3448

37. Fernández-Caggiano M, Barallobre-Barreiro J, Rego-Pérez I, Crespo-Leiro MG, Paniagua MJ, Grillé Z, Blanco FJ, Doménech N (2013) Mitochondrial DNA haplogroup $\mathrm{H}$ as a risk factor for idiopathic dilated cardiomyopathy in Spanish population. Mitochondrion 13:263-268

38. Gallardo ME, García-Pavía P, Chamorro R, Vázquez ME, GómezBueno M, Millán I et al (2011) Mitochondrial haplogroups associated with end-stage heart failure and coronary allograft vasculopathy in heart transplant patients. Eur Heart J 33:346-353

39. Tambets K, Rootsi S, Kivisild T, Help H, Serk P, Loogväli EL, Tolk HV, Reidla M, Metspalu E, Pliss L, Balanovsky O, Pshenichnov A, Balanovska E, Gubina M, Zhadanov S, Osipova L, Damba L, Voevoda M, Kutuev I, Bermisheva M, Khusnutdinova E, Gusar V, Grechanina E, Parik J, Pennarun E, Richard C, Chaventre A, Moisan JP, Barać L, Peričić M, Rudan P, Terzić R, Mikerezi I, Krumina A, Baumanis V, Koziel S, Rickards O, de Stefano GF, Anagnou N, Pappa KI, Michalodimitrakis E, Ferák V, Füredi S, Komel R, Beckman L, Villems R (2004) The western and eastern roots of the Saami - the story of genetic "outliers" told by mitochondrial DNA and Y chromosomes. Am J Hum Genet 74:661682

Publisher's note Springer Nature remains neutral with regard to jurisdictional claims in published maps and institutional affiliations. 